\title{
Grabando el prestigio social. Autoridades locales y uso político de la internet y el celular en la comunidad de Yanque (Caylloma, Arequipa)
}

\section{Mario Sánchez}

Grupo de Investigación en Antropología Visual (GIAV-PUCP)

mario.sanchez.davila@gmail.com

RESUMEN

Este artículo analiza el papel que juegan la internet y el celular (nuevas TIC) en el registro del prestigio social que hacen autoridades locales especificas en rituales y fiestas de la comunidad de Yanque en el valle del Colca (provincia de Caylloma, región Arequipa). La internet y el celular, muy lejos de desintegrar la sociedad estratificada y la tradicional cultura local yanqueñas, reafirman y refuerzan su vigencia, porque quienes usan las nuevas TIC para conseguir o mantener su prestigio social son solo aquellos que ya tienen acumuladas distintas formas de poder (dinero, tierras, objetos y conocimientos religiosos, títulos educativos), acentuando las diferencias sociales existente en el pueblo. Nueve meses de trabajo de campo se realizaron entre julio 2014 y febrero 2017.

Palabras clave: nuevas TIC, política, autoridades locales, prestigio social, Yanque. 
Recording Social Prestige. Local Authorities and Political use of the Internet and Cell Phone in the Community of Yanque (Caylloma, Arequipa)

ABSTRACT

This paper analyzes the role played by the Internet and the cell phone (new ICT) in the registration of social prestige made by local authorities in rituals and festivities of the community of Yanque in the Colca Valley (province of Caylloma, department of Arequipa). The Internet and the cell phone, far from disintegrating the stratified society and the traditional local culture of Yanque, reaffirm and reinforce its validity, because those who use the new ICT to achieve or maintain their social prestige are only those who have accumulated different forms of power (money, lands, objects and religious knowledge, educational titles), accentuating the social differences existing in the village. Nine months of fieldwork were carried out between July 2014 and February 2017.

Keywords: new ICT, politics, local authorities, social prestige, Yanque. 
Este artículo analiza el papel que juegan la internet y el celular (nuevas TIC) en el registro del prestigio social durante el rimanakuy («día de conversación»), el varamaya («limpieza de vara») y el puqllay («fiesta de carnavales») para los cargos de yaku alcalde, kamachikuq yana, rikuy, kamachikusqa, alferado y mayordomo en la comunidad de Yanque, en el valle del Colca (provincia de Caylloma, región Arequipa). Si bien existen estudios sobre el rol de la internet y el celular en la preservación de la cultura local en los Andes, no existen aún investigaciones acerca del fortalecimiento del estatus político de las familias de poder local en las comunidades andinas (Sánchez Dávila, 2016).

La comunidad de Yanque (a $3417 \mathrm{msnm}$ ) se encuentra ubicada a $150 \mathrm{~km}$ al noreste de la ciudad de Arequipa, a tres horas de camino en automóvil, por medio de una carretera asfaltada. El pueblo se inserta geográficamente dentro del valle del Colca y colinda con las comunidades de Ichupampa, Coporaque, Achoma y Chivay. A diferencia de las otras comunidades, ha ocupado una privilegiada y estratégica posición política y económica dentro del valle (Sánchez Dávila, 2017a) a lo largo de su historia pasada: como sede central del poder del señorío Collagua, que controlaba la parte norte, este y sureste del valle entre los siglos $\mathrm{X}$ y XV; como centro de administración del Tahuantinsuyu inca en el valle entre los siglos XV y XVI; como capital de corregimiento y repartimiento del virreinato español entre los siglos XVI y XVIII; como capital de la provincia de Caylloma desde mediados del siglo XIX hasta las primeras décadas del siglo XX, y como espacio turístico donde se concentra la mayor cantidad de hoteles de todo el valle desde finales del siglo XX hasta la actualidad.

El argumento central es que la internet y el celular, muy lejos de desintegrar la sociedad estratificada y la tradicional cultura local yanqueñas, funcionan como vehículos para reafirmar y reforzar su vigencia, y para reproducirla, porque quienes usan las nuevas TIC para conseguir o mantener su prestigio social son aquellos que ya tienen acumuladas distintas formas de poder (dinero, tierras, objetos y 
conocimientos religiosos, títulos educativos). Este uso de la internet y el celular remarca la diferenciación, distinción e inequidades sociales en la comunidad.

Los datos cualitativos y etnográficos fueron recogidos durante los siguientes meses de residencia en el campo de trabajo: julio-agosto, 2014; enero-febrero, 2015; julio-agosto, 2015; y diciembre-febrero, 2016-2017. La razón de esta elección se debe a que estos meses son cruciales para la agricultura (por ser temporada de lluvias, de cosechas, de sembríos y de rituales a la tierra, al agua y a las montañas) en la comunidad.

\section{TRABAJOS, RITUALES Y FIESTAS: UNA BREVE INTRODUCCIÓN}

Analizaremos trabajos, rituales y fiestas porque son las ceremonias más importantes de la comunidad, pues convocan a una gran cantidad de yanqueños y símbolos colectivos que cohesionan a Yanque durante el tiempo y el espacio de su realización: el yarqa aspiy (del 1 al 4 de agosto), el varamaya (1 de enero), el tinkachi (tercer domingo de febrero) y el puqllay (última semana de febrero). Estos son los eventos del año más concurridos, pues tienen directa injerencia en la actividad agrícola del pueblo. Y es en estos escenarios comunales donde, por un lado, surgen sentimientos de homogeneidad e igualdad y se comparte una experiencia emocional en común, pero, por otro, también aparecen marcadores de heterogeneidad y diferenciación social. Estos eventos contemporáneos, vistos localmente como tradicionales o ancestrales, son relativamente modernos con respecto a su origen, ya que muchos no datan de antes del reciente siglo XX. Por eso es que las fiestas laborales ritualizadas son plataformas de experiencias intersubjetivas puestas en escena, transmitidas generacionalmente y susceptibles de reinterpretar sus tradiciones en la práctica misma de su propio performance.

¿Qué permite la persistencia de labores, fiestas y rituales, como prácticas colectivas, en el mundo andino peruano y, en este caso, en Yanque? Plaza y Francke (1981) y Ráez (2008) ofrecen, respectivamente, una respuesta a esta pregunta. Plaza y Francke (1981) afirman que la organización colectiva tiene tres funciones motoras: (i) identidad, que hace que sus miembros se reconozcan como pertenecientes a un grupo común, cohesionados socialmente por su historia cultural compartida; (ii) representación, para velar, hacia fuera, desde una organización suprafamiliar, como potenciador de las fuerzas individuales de las familias, y (iii) defensa frente a extraños, tanto de sus recursos como de su forma de organizarse y gobernarse comunalmente. Asimismo, señalan que las labores, fiestas y rituales reafirman el respeto colectivo a las tradiciones, al reproducirse 
una estructura de cargos jerárquicos, rotativos y legitimados socialmente al interior de la comunidad.

Por su parte, Ráez (2008) señala que la persistencia de las prácticas colectivas se debe a que estas permiten la movilización y manejo de mano de obra y del conocimiento tradicional sobre el entorno, pues resulta más rentable que la organización comunitaria maneje recursos naturales de subsistencia colectiva (tierra y agua) a que estos mismos sean privatizados en relaciones contractuales, agudizando las diferencias internas económicas y políticas. Así, allí donde persisten los trabajos festivos ritualizados es porque, aunque la propiedad sea privada, las comunidades todavía mantienen la protección colectiva de los bienes y los recursos productivos, así como una fuerte organización política que determina formas de acceso a dichos recursos y a la movilización de la mano de obra laboral, y allí donde las comunidades han perdido el control colectivo de sus recursos (en aras de procesos de privatización), menos posibilidades tienen de organizar las fiestas laborales ritualizadas y se circunscriben solo al trabajo asalariado o a la renta del bien.

El calendario social de Yanque comprende tanto eventos relacionados con la producción (actividades laborales y rituales vinculadas con la actividad agrícola y ganadera) como eventos vinculados con la celebración (fiestas a santos católicos coloniales y divinidades quechuas indígenas), en tanto prácticas colectivas que cohesionan a la comunidad a lo largo del año (Benavides, 1987). Así, el calendario social muestra la persistencia de una comunidad (i) que se organiza colectivamente en torno al agua y la tierra, hecho visible no solo en sus eventos productivos, sino también en la marcación anual de su tiempo laboral-ritual (época de lluvia, época de helada, época de cosecha y época de siembra), así como la vigencia de una comunidad que (ii) se organiza colectivamente en torno al sincretismo de lo católico y lo quechua como parte de un mismo sistema religioso andino.

El trabajo (las faenas), la fiesta (la comida, la bebida y el baile) y el ritual (las ofrendas) son socialmente visibles durante los meses de febrero y agosto. Es en estos meses cuando se hacen los pagos sagrados al agua, la tierra y las montañas con la iranta (sebo de alpaca o llama, maíz, incienso, pepas y lafras u hojas enteras de coca, y cunuja, una planta resinosa con fuerte olor, y otros elementos rituales). $\mathrm{Y}$ es que, tanto en febrero como en agosto, según los yanqueños, la tierra está viva, caliente y fértil (una evidente metáfora reproductiva, una analogía entre naturaleza y biología, donde la tierra viva, caliente y fértil representa al útero ovulando y, por lo tanto, se revela también la importancia del agua como objeto seminal fecundador masculino). En febrero, época de lluvia y de carnavales, es 
cuando se realizan las danzas del carnaval o puqllay de Yanque como celebración a la fertilidad con abundante chicha y comida. Agosto, si bien es un tiempo pasivo para la producción agrícola (siembra y cosecha), es un tiempo activo para la festividad y ritualización de esta actividad (Sánchez Dávila, 2017b y 2017c).

\section{GRABANDO EL PRESTIGIO SOCIAL: APUNTES ETNOGRÁFICOS}

El 1 de agosto marca el inicio de la temporada agrícola y, con ella, el principio de la faena más relevante (llamada yarqa aspiy, yaku raymi, fiesta del agua, champería o limpieza o escarbo de las acequias principales) en Yanque. Del 1 al 4, en el nevado Mismi, montaña tutelar de Yanque Hurinsaya, y del 7 al 9 en el nevado Waranqanti, montaña tutelar de Yanque Hanansaya. Pero el yarqa aspiy de la parcialidad de Hurinsaya no solo es, en la actualidad, el evento más importante del distrito de Yanque, sino también de todo el valle del Colca, debido a la mayor cantidad de días laborales, festivos y rituales que conlleva su realización, pues su canal principal de agua (el nevado Mismi) se encuentra más alejado (a $24,5 \mathrm{~km}$ ), mientras que el canal principal de agua de la parcialidad de Hanansaya (el nevado Waranqanti) se encuentra más cerca (a $17 \mathrm{~km})$ de la comunidad (Valderrama y Escalante, 1988).

La importancia del yarqa aspiy de Yanque Hurinsaya y Hanansaya radica también —como en otras comunidades colqueñas - en la lucha concreta de muchas autoridades y usuarios, de un lado, por continuar una tradicional identidad cultural que se manifiesta en el compromiso y cumplimiento de su devoción por las divinidades quechuas y católicas, y de otro, por reafirmar y reforzar, ante Coporaque y Chivay, sus derechos legales de usufructo sobre los bienes hídricos, realizando un constante mantenimiento de la infraestructura hidráulica (Gonzales Aguilar, 2016). Asimismo, es interesante destacar que en otras comunidades que cuentan con una división bipartita en hanan y hurin, el yarqa aspiy se realiza unitariamente agrupando a ambas parcialidades (Robles Mendoza, 2010). Eso no sucede en Yanque, donde cada parcialidad tiene un yarqa aspiy determinado, ya que las fuentes de riego tanto de hurin como de hanan son diferentes y se encuentran fuera de los límites de su jurisdicción territorial.

\section{El rimanakuy o «día de conversación»}

Aunque hubo autoridades políticas prehispánicas de administración pública, tales como el aqorasi (el anciano venerable), el llaqtakamayoq (la cabeza de pueblos) 
o el tukuy rikuq (aquel que ve y escucha todo, o aquel que es ojos y oídos del pueblo), la figura del varayoq (aquel que sostiene la vara) se crea en la segunda mitad del siglo XVI como un cargo cívico-religioso con fines de administración pública colonial (Barrionuevo, 1971). Fue rápidamente aceptado por la población local indígena, como sucedió con los caciques, no solo porque se anexó al sistema de autoridades hispanas a reconocibles y respetadas autoridades aristocráticas andinas, sino también porque la sociedad indígena había tenido experiencias similares con gobernantes impuestos por el Estado incaico (Ráez, 2001).

Ciertamente, los varayoq ya no cuidan que los indios hagan sus testamentos, no velan por los huérfanos, no visitan hospitales, no controlan el funcionamiento de los mercados, no vigilan las sementeras ni los ganados, no aderezan los caminos, las iglesias, los tambos ni los puentes ni cuidan las chacras de los andenes (Barrionuevo, 1971). Indudablemente, los varayoq ya no siguen subordinados al poder local de la hacienda ni prestan apoyo a las autoridades políticas impuestas por el Estado (Ráez, 2001). Así, pues, aunque el cargo de la figura de varayoq haya perdido muchas de sus funciones coloniales y republicanas, continuó persistiendo, en tanto cargo cívico-religioso, como juez de Aguas desde 1902 hasta 1969, cuando, con la Nueva Ley de Aguas 17752 de la Reforma Agraria de Juan Velasco Alvarado, se oficializan las Comisiones de Regantes y se reconoce estatalmente la figura del regidor de Aguas, o también llamado en contextos locales varayoq, envarado, taita alcalde, alcalde de Aguas o yaku alcalde, y como miembro activo del organigrama de las Comisiones de Usuarios hasta la actualidad.

Dentro del organigrama estructural de las Comisiones de Usuarios, el yaku alcalde, con todas las responsabilidades que tiene a cargo y desempeña, se encuentra anexado formalmente como parte del área técnica de operaciones y mantenimiento. Aunque, como señalaban Valderrama y Escalante (1988), todavía hoy, y solo para el Ministerio de Agricultura, es el presidente de la comisión de regantes quien encabeza la estructura jerárquica. El presidente de la comisión de regantes es, formalmente, el mediador entre el ministerio y la comunidad con respecto a temas agrícolas. Es el representante legal de la Comisión de Usuarios del Subsector de Riego de cada parcialidad ante las reuniones del Comité de Coordinación del Distrito de Riego, con poder de votación representativa de Hanansaya o Hurinsaya, pero también ante los órganos jurisdiccionales del Poder Judicial.

Pero, en la práctica, es el yaku alcalde quien tiene el mando en la administración del agua. Así, bajo la estructura formal (la que se muestra hacia afuera) subyacen las autoridades tradicionales que dirigen el manejo del agua (que es el válido al interior de la comunidad). Y aunque oficialmente para el Estado la 
figura del yaku alcalde solo tenga importancia cívica (en tanto gestor técnico del agua), en la comunidad la figura del yaku alcalde también tiene importancia política y, por ello, pasar el cargo de yaku alcalde otorga prestigio social. Podemos ver, así, cómo el yaku alcalde se desenvuelve en el ámbito formal (autoridades y funciones definidas por una estructura legal de gobierno estatal), el informal (autoridades y funciones definidas por patrones locales de prestigio personal), el interno (códigos culturales de organización específicos de cada autoridad local) y el externo (capacidad de relacionarse con instancias exógenas), al igual que otras autoridades locales dentro de escenarios rurales (Damonte, 2000; Ráez, 2002). Por eso los cargos cívico-religiosos son de duración limitada y rotativos; tienen funciones específicas, trajes habituales y atributos determinados, y están jerarquizados entre sí (Diez, 2005).

Desde el punto de vista productivo, el yaku alcalde es el facultado para regir, a través de un conjunto de normas reglamentarias, el acceso comunal de los usuarios al agua. De esta manera, de acuerdo con el Manual de Organización y Funciones de la Comisión de Usuarios de Yanque Hurinsaya (2015), el yaku alcalde se encarga, principalmente, de (i) llevar el registro de apertura y el cierre de compuertas, así como de los caudales medidos en las tomas a su cargo formulando su parte diario; (ii) regular las compuertas de las tomas de los canales de derivación a su cargo, según el rol de distribución; (iii) controlar el caudal del agua que discurre por las tomas a su cargo; (iv) vigilar que las compuertas de las tomas a su cargo no sean operadas por personas ajenas; (v) efectuar labores de limpieza de las tomas de captación a su cargo e informar cuando estas labores requieran la participación de los usuarios; (vi) mantener en buen estado los precintos y demás sistemas de seguridad de las tomas; (vii) efectuar el reparto diario de agua según el rol de riego de distribución que establezca el jefe de Sector o Subsector de Riego; (viii) elaborar los partes diarios de distribución de agua por usuario y por predio; (ix) controlar las limpiezas y reparaciones de los canales, tomas, drenes y caminos de vigilancia de su zona de trabajo, así como de las reparaciones de las obras de conservación y control de inundaciones; (x) informar sobre las infracciones en la distribución y aprovechamiento del agua, así como de los problemas de manejo de agua y del suelo; (xi) colaborar en la distribución y recepción de solicitudes de plan de cultivos para plan de riegos, y (xii) informar a los usuarios sobre eventuales cortes de agua, ya sea por limpieza del canal principal, por alguna obra de canalización u otro motivo.

Desde el punto de vista religioso, el yaku alcalde es el facultado para acercar a los comuneros (lo humano) con el agua, la tierra y las montañas (lo divino). 
Precisamente por ello no es coincidencia que la palabra quechua yaku se utilice para denominar al agua en tiempos profanos, mientras que la palabra aimara mallku, aunque signifique antepasado, se utilice para denominar al agua en tiempos sagrados.

En la comunidad de Yanque existen cuatro yaku alcaldes: dos para la parcialidad de Hanansaya (con propiedad de las varas de Waranqanti y Ticlla) y dos para la parcialidad de Hurinsaya (con propiedad de las varas de Mismi y Sifón). Y todo comunero que tenga más de cinco topos de tierra tiene la obligación de pasar por el cargo de yaku alcalde si es que esto es solicitado por el resto de usuarios. Esta obligación de compromiso y colaboración exime al yaku alcalde de recibir un pago formalmente establecido de dinero (como si se tratase del pago de un sueldo en una relación contractual), aunque sí recibe la suma variable de las voluntades económicas de los comuneros que le brinda una ayuda simbólica por parte de los miembros de la Comisión de Regantes (para los gastos que aparecen en el ejercicio de sus funciones como gestor del recurso hidráulico) y una retribución simbólica por parte de los demás comuneros (por los gastos que requiere el desempeño de sus funciones como responsable del ritual y organizador de la fiesta).

El 31 de julio de 2015 se llevó a cabo el rimanakuy en la casa del yaku alcalde (Gil Rivera, 52 años), una celebración ritual donde el mismo yaku alcalde y otras autoridades, tales como el kamachikuq yana (especialista, Isidro Suni, 65 años), el rikuy (servidor del yaku alcalde, Mauro Inca, 41 años) y el kamachikusqa (ayudante del yana, Sixto Suni, 43 años), construyen doce irantas (hechas de sebo de alpaca o llama, maíz, incienso, pepas y lafras u hojas enteras de coca, y cunuja, entre otros elementos rituales) que son quemadas para saludar, pedir permiso y bendiciones para el camino y la estadía al Tata Mismi, al Tata Waranqanti y al Tata Colca, así como agradecimientos al padrino, la madrina, al Niño Manuelito y a las dos varas sagradas del yaku alcalde. En la tarde de ese día, el yaku alcalde y su familia preparan pan y humitas con queso, y limpian y acomodan su casa para poder recibir a los usuarios de la parcialidad de Hurinsaya a partir de las seis de la tarde. Todo ello en vísperas a la madrugada siguiente, cuando la comunidad parte rumbo al nevado sagrado Mismi para trabajar, festejar y ofrendar por tres noches y cuatro días al Tata Mallku y a la Mamapacha.

Desde la misma tarde del rimanakuy pudimos observar los usos de las nuevas TIC en los contextos rituales de Yanque. Comenzó con la presencia del joven hijo del yaku alcalde (del 2015), a quien su padre le había pedido que grabe para poder después mostrárselo al resto de la familia que no iba a poder asistir al evento. Así, por ratos con una filmadora y por ratos con su celular, él seguía a todos. Desde 
las escenas más privadas hasta las más públicas, todas las grababa. Cuando aún nadie llegaba, seguía a su madre, la esposa del yaku alcalde, mientras preparaba la comida para todos los comuneros que iban a asistir a la reunión de la noche. Seguía con el celular a su tío, hermano del yaku alcalde, mientras preparan pan y humitas con queso, y mezclaba los baldes de almidón y alcohol para compartirlo en la noche con los usuarios. Grababa, asimismo, el lento proceso de cómo el yaku alcalde, el kamachikuq yana, el rikuy y el kamachikusqa construían las irantas y se realizaban los pagos en la habitación y con todos los asistentes, que esperaban en línea para mostrar sus respetos levantando en el aire y soplando tres veces las irantas que serían quemadas luego en una hoguera. Grababa cómo vestían al Niño Manuelito (una adaptación del Niño Jesús para el mundo andino, cuya representación es acompañada por un sombrero, un traje de colores y una vara a escalas). Grababa también el proceso de sahumado de las dos varas del yaku alcalde (Juan de la Cruz y Presentación). Grababa, por último, al yaku alcalde, al presidente de la comunidad, al presidente de la Comisión de Regantes de la parcialidad de Hurinsaya y al alcalde municipal sentados en la misma mesa frente a los demás comuneros y usuarios de Yanque, al caer la noche, coordinando los pormenores para la ida al nevado Mismi esa misma madrugada, y brindando, entre ellos, con almidón y chicha de maíz y cebada.

Durante todo el rimanakuy, tanto el yaku alcalde como su hijo señalaban que el objetivo de grabar estas escenas era preservar las costumbres de la cultura yanqueña para que no se perdieran. Entonces, en ese contexto, las nuevas TIC estarían - porque veremos que, en el fondo, no se trata solo de eso- siendo usadas para registrar audiovisualmente una tradición ritual para perpetuarla, porque, además, se veía amenazada, según el yaku alcalde, de desaparecer por la influencia de agentes exógenos como la carretera y el turismo. Y es que, aunque esas costumbres aún están vivas en la comunidad, la necesidad de preservarlas surge de la percepción de un creciente retroceso. No obstante, por lo menos hasta ahora, muchos en la comunidad no quieren que la tradición del yarqa aspiy se detenga. «Es costumbre. Hay que seguir manteniéndola», dice el kamachikuq yana, así como dicen también muchos comuneros viejos de Yanque, aludiendo que esa tradición es parte de la identidad que les han dejado sus abuelos; así, si esta tradición se pierde, ellos pierden también su identidad o, por lo menos, la vigencia de su identidad heredada del pasado. En ese sentido, parece ser que tradiciones como el yarqa aspiy funcionan, entre otras cosas, como un nexo que los comuneros de Yanque, sobre todo los adultos, preservan para no desvincularse de la cultura de sus padres, abuelos y demás ancestros. 
Entonces, todo parecía indicar que el rimanakuy era una oportunidad para que las nuevas TIC posibilitaran la grabación de todas esas escenas con el fin de preservar y perpetuar audiovisualmente una tradición para que no sea olvidada. $Y$ es que los yanqueños que utilizan el audio y el video son muy conscientes de su funcionalidad - la imagen que no se pierde, que no se desgasta, que puede ser vista y oída aquí y allá- para conseguir su objetivo de conservar una parte de su cultura. Sin embargo, unas semanas después tuvimos la oportunidad de ser invitados por el yaku alcalde a su casa para ver, con su familia, estas grabaciones. Y nuestra impresión cambió. Sabíamos ya que pasar el cargo de yaku alcalde otorga prestigio social, ya que, desde el punto de vista productivo, este es el facultado para regir, a través de un conjunto de normas reglamentarias, el acceso comunal de los usuarios al agua, pero también, desde el punto de vista simbólico para acercar a los comuneros (lo humano) con el agua, la tierra y las montañas (lo divino). Y aunque, como ya se vio, para el Estado la figura del yaku alcalde solo tenga importancia cívica (en tanto gestor técnico del agua), para la comunidad la figura del yaku alcalde también tiene importancia ritual. Pero la figura del yaku alcalde es voluntaria solo en apariencia, pues es, de hecho, obligatoria debido a la gran inversión de tiempo y dinero, haciendo que los comuneros que tienen más de cinco topos de tierra se disputen no por pasar el cargo, sino por no pasarlo (Gonzales Aguilar, 2016), pues, por todos estos gastos, es un cargo aún más valorado socialmente.

Por eso comprendimos que, en ese contexto, grabar no solo significaba un acto de preservación cultural sino también un registro del prestigio social. Nos sentamos al pie de la cama y miramos cómo ellos, el yaku alcalde y su familia, se veían a sí mismos. Todos observábamos el video cuando, de pronto, el yaku alcalde dijo: «Con esto [la grabación] recordaré que alguna vez fui regidor [de Aguas] y cumplí humildemente con mi cargo dando nuestra casa y nuestro tiempo para nuestros hermanos [comuneros]». También le pidió a su hijo que colgase el video en internet para que sus familiares que no habían asistido pudieran ver «que he sido regidor [de Aguas] y que hice algo por nuestro pueblo». Así, a través de las grabaciones no solo se conservaba una tradición cultural, sino que también se registraba y se circulaba el prestigio social que había obtenido el yaku alcalde por haber pasado el cargo. Y es que el cargo era tan importante para el yaku alcalde que nos pidió que le tomáramos fotos a él cumpliendo sus obligaciones rituales durante los cuatro días que estuvimos en el Mismi. Después, cuando le entregamos las fotografías impresas, las colgó en la pared en el comedor de su casa, junto a las dos varas y al Niño Manuelito. 


\section{El varamaya o «limpieza de vara»}

No solo en el rimanakuy encontramos los usos de nuevas TIC para la preservación de la cultura y el registro del prestigio social. Otro contexto ritual en donde también aparece este mismo uso lo hallamos en el varamaya. Ese día, 1 de enero de 2017, las autoridades políticas, después de haber subido al Mismi para hacer el pagachi (pagos rituales al agua, la tierra y las montañas) el 31 de diciembre de cada año, se reúnen en la casa del yaku alcalde (de 2016) para realizar la costumbre de limpiar la vara con alcohol.

La vara es una insignia de mando precolombina, aunque a partir del período colonial, con el cargo de varayoq, la vara, hecha de madera y metal, posee símbolos sincréticos religiosos tanto católicos (el crucifijo) como quechuas (el sol, la luna, las plantas y los vegetales, así como también figuras geométricas). Por eso, las varas son bendecidas en la iglesia por los curas, reconociendo el poder que han ostentado por siglos y marcando el inicio del año de regiduría, sin posibilidad de reelección del yaku alcalde. Y, por eso, la vara como símbolo de autoridad local (Arguedas, 1985; Valderrama y Escalante, 1988; Ramírez León, 2014) posiciona al varayoq (aquel que sostiene la vara) no solo como yaku alcalde (alcalde o regidor de Aguas), sino también como el representante comunal en contextos rituales: no solo comunica a la comunidad con la naturaleza a partir de la productividad, sino también a partir de lo ritual, actualizando, con ayuda de un kamachikuq yana (el especialista), de un rikuy (el servidor del yaku alcalde) y de un kamachikusqa (el ayudante del yana), las costumbres políticas andinas, constituyendo así la memoria viva que hace posible la persistencia de conocimientos ceremoniales.

Y es que si el yaku alcalde es el sujeto intermediario entre lo profano y lo sagrado, la vara es el objeto intermediario entre la comunidad y el Tata Mallku y la Mamapacha. Por eso, la vara tiene nombre (bautizada como Juan de la Cruz y Presentación en Hurinsaya y como Tomás y Guardia Civil en Hanansaya), tiene cuerpo (una vez sahumada para limpiarla, es vestida para que no sienta el frío de la montaña y adornada con wayta, planta que también adorna los sombreros de los comuneros más importantes), y tiene condición (guardada en un altar al interior de la casa). En definitiva, la vara tiene vida propia. Según Valderrama y Escalante (1988), existen otros nombres de bautizo para las varas que se encuentran relacionados con fechas centrales del calendario religioso católico: por ejemplo, el 25 de diciembre se les denomina Manuel (por Jesús); el 1 de enero se les denomina Silvestre (por San Silvestre), y el 2 de febrero, se les denomina Tomás (por la Virgen de la Candelaria). Tal es la relevancia social de la vara en Yanque que, 
después del ascenso al Mismi para hacer el pagachi el 31 de diciembre de cada año, las autoridades económicas y políticas se reúnen en la casa del yaku alcalde para llevar a cabo el tradicional varamaya o limpieza de la vara (con alcohol).

En este escenario se insertan las nuevas TIC. Así como sucedió con el yaku alcalde de 2015, en esta ocasión también es el hijo del yaku alcalde (de 2016) quien se encuentra encargado de grabar con su celular todas las escenas de la ceremonia. Este elemento generacional es una recurrencia importante en el uso de las nuevas TIC en Yanque, ya que los niños y jóvenes se encuentran mejor capacitados que los adultos para usar la internet y el celular. Pero, interesantemente, son los padres los que hacen que los niños y jóvenes formen parte de las fiestas y rituales dándoles el cargo de fotografiar o filmar, logrando, a través de esta acción pedagógica, que las nuevas generaciones se socialicen y aprendan los conocimientos de dichas prácticas sociales.

Entonces, en el varamaya se bebía chicha, se comía, se bailaba, pero lo más importante era que todas estas actividades se desarrollaban alrededor de la mesa central donde el yaku alcalde se encontraba sentado, al lado de otras autoridades políticas, como el alcalde municipal, el kamachikuq yana, el rikuy y el kamachikusqa. La gente del pueblo hacía cola hasta afuera de la casa para poder agradecer económicamente al yaku alcalde. La compra de alcohol para la limpieza de la vara se encontraba dividida entre mayoristas (quienes poseen más de cinco topos de tierra), que compraban la mayor cantidad de alcohol, y minoristas (quienes poseen menos de cinco topos de tierra), que compraban apenas una pequeña botella de alcohol o alcohol en bolsa.

Alrededor de la mesa, mientras unos ancianos ya estaban ebrios y las mujeres comían, los usuarios hacían fila para rendir sus respetos ya no solo al yaku alcalde, sino, y sobre todo, a la vara. Uno a uno iban vertiendo la cantidad de alcohol que habían comprado sobre la vara que sostenía el rikuy (asistente del yaku alcalde). El hijo del yaku alcalde (de 2016) seguía con su celular cada una de estas escenas porque - como afirmaba él- «hay que mantener nuestras costumbres». Y en todas estas escenas públicas, el yaku alcalde siempre se había mostrado orgulloso, pues no era ningún secreto que este cargo es una forma de autoridad local que otorga estatus a quien lo pasa. Ese orgullo se evidenciaba en la solemnidad que desplegaba cuando se dirigía al resto de usuarios y comuneros como un líder. O cuando recibía, célebre, los aplausos de las autoridades políticas no solo durante lo que duró el varamaya, sino también el día anterior, cuando estuvieron en el Mismi para realizar la costumbre del pagachi. Ciertamente, la preservación de la tradición cultural era el objetivo más evidente e, incluso, explícito, pues tanto 
el yaku alcalde como su hijo señalaban la importancia de que no se pierdan los elementos tradicionales de su cultura. Pero, como sucedió en el caso anterior, las fotografías y videos no solo servían para perdurar la tradición cultural sino también para registrar el prestigio social que el yaku alcalde había obtenido como pasante del cargo productivo-religioso y como auspiciador del varamaya.

\section{El puqllay $o$ «fiesta de carnavales»}

Finalmente, encontramos estos mismos usos de las nuevas TIC en el puqllay o la fiesta de carnavales, que se celebra durante toda la última semana de febrero, y donde compiten la parcialidad de Yanque Hurinsaya y Yanque Hanansaya. Es una fiesta que involucra a gran parte de la comunidad.

La dualidad entre hanan y hurin se encuentra todavía vigente en Yanque, y tiene como punto central de referencia a la iglesia de la comunidad, desde donde se marca una división espacial y simbólica entre los residentes de Hanansaya y Hurinsaya (Cook, 2011), comprometiéndolos a participar en las labores, fiestas y rituales de su respectiva parcialidad (Valderrama y Escalante, 1988; Benavides, 1991). La vigencia de la división hanan (este-superior) y hurin (oeste-inferior) aparece en el cementerio de la comunidad, donde cada parcialidad ocupa una mitad específica del cementerio (Benavides y Llosa, 1994), donde solo a partir de mediados del siglo XIX, por ordenanza obispal nacional, comenzaron a ser sepultados los fieles, pues antes los entierros se realizan dentro de los templos, atrios y conventos (Benavides, 1988). Pero esta división dual también está vigente en el hecho que cada parcialidad tenga que manejar un sistema hidráulico de forma independiente (Ráez, 1998), con conflictos con respecto a tomas comunes, un problema que no existía prácticamente hasta que se abolió el cacicazgo, cuando el control de riego era todavía un asunto provincial (Bernal, 1983; Benavides, 1988a). Y recordemos también que, en la actualidad, el canal principal de riego de Yanque Hanansaya (cuyas tierras agrícolas se encuentran junto al pueblo) y de Yanque Hurinsaya (cuyas tierras agrícolas se encuentran frente al río) son, respectivamente, las aguas del nevado Waranqanti y del nevado Mismi. No obstante, actualmente, la parcialidad de Yanque Hanansaya no solo cuenta, para el riego agrícola, con el canal Waranqanti, sino también los canales Ticlla, Sifón y Majes. Este hecho hace que dicha parcialidad tenga muchos menos problemas con el agua de riego que la parcialidad de Hurinsaya, y, tal vez, sea esta necesidad que hace que los pobladores de Hurinsaya estén mucho mejor organizados con los trabajos, fiestas y rituales. Y, por último, vale mencionar que el hecho 
de que un comunero sea reconocido como parte de y que posea tierras en una parcialidad específica - Hurinsaya o Hanansaya - no lo excluye, en la práctica, de tener topos en la parcialidad a la que formalmente no se encuentra adscrito.

Todos los años, una familia se devota, en calidad de alferados, para pasar el cargo de hacerse responsable por la fiesta y todo lo que ello implica: contratar a las bandas de músicos, preparar la comida, hacer la chicha de maíz y cebada, asegurarse que la gente se comprometa a bailar wititi durante todo el día y la noche, entre otras cosas. Tres hermanos de la familia Suni se habían comprometido con la comunidad para hacer posible la realización del puqllay a fines de febrero de 2017.

Tuvimos la oportunidad de asistir, temprano por la mañana, a la casa de los alferados y mirar cómo ellos, sus parientes y amigos se vestían, hombres y mujeres, con los trajes del baile del wititi — una danza reconocida por la UNESCO, en 2015, como patrimonio cultural inmaterial de la humanidad - presente en muchos distritos del valle del Colca, aunque en Yanque adquiere un propio estilo performativo, desde la vestimenta hasta el baile (según yanqueños de mayor edad, el wititi, donde los hombres usan faldas y antifaces coloridos, tenía una doble función: por un lado, como una danza para sacar a las mujeres de sus casas con engaños y sin que sus padres se percataran de ello, y por otro, como una danza para confundir a los enemigos en batalla).

Tuvimos también la oportunidad de ver llegar a las dos bandas de música y de escucharlas, desde sus inicios, interpretar las melodías del wititi y mirar a la gente comenzar a bailar con mucha felicidad. No obstante, creemos que la oportunidad más aprovechable que tuvimos fue la de observar cómo la familia había contratado, días atrás, en Chivay, a alguien que grabara los pormenores de toda la fiesta, desde la mañana hasta la madrugada. El fotógrafo-filmador no solo sugería posturas a los alferados, sus parientes y amigos para ser fotografiados: también los orientaba a que le hablen a la cámara. Los tres alferados mandaban saludos a aquellos parientes que no pudieron estar en Yanque para esos días de fines de febrero. Los tres hermanos señalaban que habían contratado a esta persona porque «son costumbres de nuestros abuelos que se están perdiendo». La cámara de foto y video tenía, entonces, el objetivo de registrar las costumbres para preservarlas. Al mediodía, los alferados, sus parientes y amigos, al ritmo de ambas bandas de música tocando wititi, se fueron danzando hasta la plaza del pueblo para comenzar, después de hacer las correspondientes reverencias a la iglesia de Yanque, la competencia entre parcialidades que duró hasta la madrugada. Cada parcialidad estaba representada por una cuadrilla de músicos y danzantes, ubicados una frente a la otra en el centro de la plaza de la 
comunidad. Competían — como ellos mismos señalaban — por ver y mostrar qué cuadrilla bailaba mejor y tocaba más fuerte, y, por ello, qué parcialidad era mejor que la otra. Desde la tarde hasta la noche, lo que estuvo en juego simbólico fue el prestigio social de las parcialidades de Hurinsaya y Hanansaya.

Pero esta búsqueda de prestigio social no podría haber sido posible sin los alferados. El hecho de que los yanqueños de Hurinsaya hayan podido competir para conseguir estatus se encuentra relacionado con el hecho de que los hermanos Suni hayan donado ambas bandas de música y conseguido los danzantes. Los responsables indirectos del prestigio social que llegó a ganar la parcialidad de Hurinsaya fueron quienes otorgaron las condiciones para que ese estatus sea buscado y ganado. En ese sentido, el registro de las costumbres y de las tradiciones culturales de Yanque en fotos y videos comprende solo una parte de los usos de las nuevas TIC en este contexto festivo. La otra cara del uso de las fotos y el video es - ya que las grabaciones se centraron principalmente en los alferados desde la mañana hasta la madrugada - registrar también el poder de los hermanos Suni para hacer realizable no solo la tradicional fiesta de carnavales, donde acude gran parte de la comunidad, sino, también, para hacer que su parcialidad pueda competir y ganar estatus.

Todas las grabaciones de las cuales hemos hablado anteriormente son puestas en redes sociales como Facebook o YouTube. Es en esta última donde han tenido una alta cantidad de visualizaciones. Quienes difunden los trabajos, rituales y fiestas son, en su mayoría, las productoras contratadas por las familias para filmar estos eventos. A continuación, los casos más sobresalientes. Una de las productoras que más eventos yanqueños filma, edita y difunde es Producciones Mar y Sol, del yanqueño Noé Huaracha Cutipa. En su canal podemos ver, por ejemplo, que se muestra cómo la familia de mayordomos Jesús Casaperalta Cáceres y Gladys Cáceres de Casaperalta se hacen cargo de la realización de la fiesta patronal en honor a San Antonio de 2018 y de la fiesta de carnavales de 2017 en Yanque Hanansaya. Por su parte, la productora Filmaciones Cóndor realizó un video de la familia Rivera Rivera pasando el cargo, en 2015, de la fiesta de carnavales. Yans Producciones hizo un video, en 2016, de la familia Rivera Quispe pasando el cargo de la fiesta de San Antonio de Padua. Asimismo, Usfer Producciones efectuó un video de la festividad en honor a la Santísima Virgen del Chapi del 2018 y de los mayordomos Rosinaldo Huanaco Suyco y Rosalía Suyco. Así también, Julius Films desarrolló, en 2018, un video, filmado con drones, de la fiesta de San Antonio de Padua que pasaron Isidro Suni Rivera y Gregoria Sarayasi.

El hecho de que las familias que se hacen cargo de la realización de las fiestas contraten los servicios de filmación de las productoras de Chivay no es algo gratuito. 
La grabación de estos escenarios festivos no solo pone en evidencia la profunda experiencia simbólica que viven los yanqueños a través del baile, el alcohol y la religiosidad, sino que también muestra un espacio para la marcación de la diferenciación social. En un nivel explícito, el hacerse cargo de la fiesta constituye una acción voluntaria y desinteresada amparada en la devoción religiosa (aunque incluso ahí ya se podría señalar la búsqueda de un interés al trazar una relación de reciprocidad en dar, recibir y devolver con el santo). Pero en un nivel implícito comprendemos que la solvencia que tiene la familia donante para regalar una experiencia simbólica a la comunidad beneficiada es, en última instancia, el marcador definitivo de la distinción entre quien da y quien recibe y no puede devolver. Y es esa diferenciación, esa distinción, la que es capturada y perpetuada en un material audiovisual producido y conservado por las familias de poder, pero también circulada y reproducida en internet para perdurar en el tiempo como testimonio, como evidencia de una posición económica y política privilegiada dentro del pueblo.

\section{REGISTRANDO LA DIFERENCIA SOCIAL: A MODO DE REFLEXIÓN FINAL}

Afirmar que las nuevas TIC son usadas para preservar la cultura es mostrar el rostro más inocente de un proceso de perpetuación global de lo que ya existe localmente: la lengua, la gastronomía, los trajes, los bailes, la música, los sitios arqueológicos, los mitos y ritos, las costumbres y tradiciones. La otra cara de este proceso es que no solo se preservan objetos y prácticas culturales, sino también jerarquías sociales. De este modo, las nuevas TIC también sirven para reproducir las inequidades sociales y el poder de las familias privilegiadas de Yanque.

Son las familias yanqueñas que se encuentran mejor posicionadas económicamente las que han logrado insertarse y mantenerse sostenibles en el turismo rural comunitario los últimos años. Así, pues, solo una minoría de familias vienen incrementando sus recursos económicos a través de las nuevas TIC; es decir, las mismas familias que ya tenían recursos económicos para invertir, entre otros, en nueva y mejor infraestructura que acondiciona su casa en hospedaje rural, y en saberes técnicos alrededor de la internet y sus posibilidades de aprovechamiento turístico (los Suni, Málaga, Checa, Huaypuna y Huaracha).

Los registros del Padrón General de Usuarios de las parcialidades de Yanque Hurinsaya y Yanque Hanansaya (2013) revelan que los apellidos Checa, Huaracha, Inca, Llaza, Mamani, Rivera y Vilcazán no solo son los más recurrentes, sino que además pertenecen a quienes concentran la mayor cantidad de topeaje (quince 
topos en promedio por persona). Dicha cifra es importante si se toma en consideración que la mayoría de los usuarios no supera los cinco topos de tenencia de tierras agrícolas, donde, según la etnoclasificación de usuarios a partir de la tenencia de tierras, los que poseen entre uno y cinco topos son minoristas, los que poseen entre cinco y ocho topos son medianos, y los que poseen entre ocho a veinte topos son mayoristas; es decir, una minoría de familias yanqueñas son mayoristas, mientras que una mayoría de familias yanqueñas son minoristas. Este hecho evidenciaría que una estratificación económica-política a partir de la distribución inequitativa de la tenencia de tierras.

Por último, hay familias de poder económico que tienen un mayor acceso al manejo del poder político en la comunidad. En Yanque, varios relatos mitológicos de ambas parcialidades del distrito (Cook, 2011; Pease, 2014; Valderrama y Escalante, 1997) revelan el posicionamiento histórico de las familias de élite, como los Choquehuanca de Hanansaya (el cacique de la parcialidad de Hanansaya que hizo construir el canal que dirigía las aguas del Waranqanti a esta parcialidad se apellidaba Choquehuanca, según Zevallos, 2006) y los Checa de Hurinsaya (el principal curaca prehispánico de la parcialidad de Hurinsaya, como aparece en el censo de 1586, se llamaba García Checa, según Cook, 2011). Así, el prestigio político que ostenta la familia Checa se ve legitimado por el nivel mitológico e histórico. Y es que solo los hombres de la familia Checa poseen el derecho reconocido, además, por la comunidad - de hacer ofrendas en la montaña Mama Umahala (mujer y compañera del Tata Mismi, y ubicada a mitad del recorrido), porque fueron tierras de los Aukay Ch'eqa en tiempos prehispánicos (hecho que revela cómo diferentes formas de cargos hereditarios de linaje son nuevas formas de cacicazgos).

Es por eso que, así como el yaku alcalde y su yana son los representantes de la comunidad ante el lado masculino del agua, los Checa son los representantes de la comunidad ante el lado femenino del agua (Valderrama y Escalante, 1988), dependiendo de ambos la realización anual de la fiesta laboral ritualizada, la ceremonia más importante de la comunidad, llamada yarqa aspiy. Así también podemos ver el prestigio político (fue, en su momento, yaku alcalde) que ostenta Gerardo Huaracha, uno de los últimos ganaderos y propietarios de grandes extensiones de terrenos dentro de la comunidad de Yanque. Actualmente, es uno de los últimos testigos vivos de la batalla de Chachayllo y nieto de Félix Huaracha Ríos, el último cacique de la parcialidad de Yanque Hurinsaya.

Vistas así las cosas, no es raro que quienes más se oponen a la supuesta desaparición de mitos y rituales sean los que han pasado (adultos mayores) o 
van a pasar (adultos) cargos políticos, invocando, explícitamente, a la necesidad de proteger las tradiciones y costumbres locales: existe, pues, una preocupación por preservar la cultura local. Pero, en un nivel mucho menos evidente, podemos darnos cuenta de que, si desaparecen los rituales y mitos, desaparecen también los cargos políticos que permiten su producción y reproducción, y, con ellos, desaparece, asimismo, la posibilidad de obtener prestigio social a través de una dimensión que no sea la económica.

Así, pues, las nuevas TIC sirven para que quienes dominan reafirmen su poder político y su posición privilegiada dentro del campo social estratificado de la comunidad. Y no es casualidad que las familias que tienen más topos de tierra o cabezas de ganado (las familias pudientes, desde la dimensión económica), sean las mismas que tienen acumulado prestigio social por haber pasado o pasar cargos políticos dentro de la comunidad o que, precisamente por su capital económico, han podido insertarse exitosamente en el turismo rural comunitario. A ello habría que añadir que a menudo quienes concentran estos tres poderes (el dinero, la tierra y los conocimientos) son las familias privilegiadas de Yanque.

Y he ahí justamente el dilema del uso político de las nuevas TIC en la comunidad de Yanque en el valle del Colca. Por un lado, la internet y el celular sirven para salvaguardar la cultura local de la comunidad, permitiendo la revitalización de la lengua, la gastronomía, los trajes, los bailes, la música, los sitios arqueológicos, los mitos y ritos, las costumbres y tradiciones dentro de un escenario local-nacional-global del siglo XXI. Por otro, los motivos de dicha apuesta revitalizadora de la cultura yanqueña no son gratuitos, pues esta les sirve a las familias de poder para reforzar su prestigio social. Y si en buena medida, hay cargos que son impuestos (y no elegidos voluntariamente), no son impuestos a cualquiera: es una obligación moral para los que más han acumulado o heredado, pero una obligación que deviene luego en notoriedad social. Y es que no cualquiera puede tener el prestigio social que produce un estatus dominante, porque no cualquiera puede acceder a ser alferado o devoto de una fiesta, participantes del turismo rural comunitario o a la presidencia de la Comisión de Turismo (solo los que más dinero tienen); no cualquiera puede acceder a ser yaku alcalde o acceder a la presidencia de la Comisión de Regantes o a la presidencia de la comunidad (solo los que más tierras tienen); no cualquiera puede acceder a ser rikuy, kamachikusqa o kamachikuq yana (solo los que tienen más conocimientos y objetos religiosos heredados de sus padres o abuelos). En ese contexto, los que más tienen (dinero, tierras, conocimientos) usan las nuevas TIC para reforzar su notoriedad social, reproduciendo así las inequidades económicas y políticas existentes en el pueblo. 


\section{REFERENCIAS}

Arguedas, José María (1985). Indios, mestizos y señores. Lima: Horizonte.

Barrionuevo, Alfonsina (1971). El Varayoq. Equilibrador entre dos mundos. Lima: CIBA.

Benavides, María (1987). Apuntes históricos y etnográficos del valle del río Colca (Arequipa, Perú), 1575-1980. Boletín de Lima, 50, 7-20.

Benavides, María (1988). La división social y geográfica Hanansaya / Urinsaya en los pueblos del Colca y la provincia de Caylloma (Arequipa, Perú). Boletín de Lima, 60, 49-53.

Benavides, María (1991). Dualidad social e ideología en la provincia de Collaguas, 1570-1731. Historia y Cultura, 21, 127-160.

Benavides, María y Héctor Llosa (1994). Arquitectura y vivienda campesina en tres pueblos andinos: Yanque, Lari y Coporaque en el valle del río Colca, Arequipa. Bulletin IFEA, 23(1), 105-150.

Bernal, Alfredo (1983). Danzas de la etnia collaguas y colonias: un estudio en la cuenca del Colca, Caylloma. Tesis, Arequipa: Universidad Mayor de San Agustín.

Comisión de Usuarios de Yanque Hurinsaya (2015). Manual de organización y funciones $(M O F)$. Yanque, Caylloma, Arequipa.

Cook, Noble David (2011). Los hijos del volcán. Dualidad andina en el Valle del Colca. Arequipa: El Lector.

Damonte, Gerardo (2000). Apuntes sobre el teniente gobernador. En Juan Ansión, Alejandro Diez y Luis Mujica (eds.), Autoridades en espacios locales: una mirada desde la antropología (pp. 109-124). Lima: PUCP.

Diez, Alejandro (2005). Los sistemas de cargos religiosos y sus transformaciones. En Manuel Marzal (ed.), Religiones campesinas (pp. 253-286). Madrid: Trotta.

Gonzales Aguilar, Maira (2016). Políticas hídricas y derechos de agua: cambios y continuidades en la organización social del riego en la comunidad de Yanque. Tesis de licenciatura. Lima: PUCP.

Padrón General de la Comisión de Usuarios de Yanque Hanansaya y Hurinsaya (2013). Lista de usuarios con cantidad de topeaje. Yanque, Caylloma, Arequipa.

Pease, Franklin (2014). Del Tawantinsuyu a la historia del Perú. Lima: PUCP.

Plaza, Orlando y Marfil Francke (1981). Formas de dominio, economía y comunidades campesinas. Lima: Desco. 
Ráez, Manuel (1998). Los ciclos ceremoniales y la percepción del tiempo festivo en el Valle del Colca (Arequipa). En Raúl Romero (ed.), Música, danzas y máscaras en los Andes (pp. 253-297). Lima: PUCP.

Ráez, Manuel (2001). Jerarquía y autoridad comunal. Los varayos y la Fiesta de Agua de la comunidad campesina de Lachaqui, Canta. En Gisela Cánepa Koch (ed.), Identidades representadas. Performance, experiencia y memoria en los Andes (pp. 331-368). Lima: PUCP.

Ráez, Manuel (2002). En los dominios del cóndor. Fiestas y música tradicional del Valle del Colca. Lima: PUCP.

Ráez, Manuel (2008). Celebrando el trabajo. En Raúl Romero (ed.), Fiesta en los Andes. Ritos, música y danzas del Perú (pp. 102-139). Lima: PUCP.

Ramírez León, Luis (2014). La vara de mando popular y tradicional en el Perú. Lima: UNMSM.

Robles Mendoza, Román (2010). Sistemas de riego y ritualidad andina en el Valle del Colca, Revista Española de Antropología Americana, 40(1), 197-217.

Sánchez Dávila, Mario (2016). Nuevas TIC en los Andes peruanos: fundamentos teóricos y balance bibliográfico. Contratexto, 26, 133-159. Lima: Universidad de Lima.

Sánchez Dávila, Mario (2017a). Yanque en el valle del Colca (Caylloma, Arequipa). Historia y cultura en los siglos XV-XX. Haucaypata (Investigaciones Arqueológicas del Tahuantinsuyo, Perú), 6(12), 68-78.

Sánchez Dávila, Mario (2017b). Comprender la agricultura en los Andes peruanos. Economía y política en la comunidad de Yanque (Caylloma, Arequipa). Antropologías del Sur, 4(7), 235-256. Chile: Universidad Academia de Humanismo Cristiano.

Sánchez Dávila, Mario (2017c). Comprender la agricultura en los Andes peruanos. Religión en la comunidad de Yanque (Caylloma, Arequipa). Revista Peruana de Antropología, 3(3), 9-19. Perú: Universidad Nacional de San Agustín.

Valderrama, Ricardo y Carmen Escalante (1988). Del Tata Mallku a la Mama Pacha. Riego, sociedad y ritos en los Andes peruanos. Lima: Desco.

Valderrama, Ricardo y Carmen Escalante (1997). La doncella sacrificada. Mitos del Valle del Colca. Lima: IFEA.

Zevallos, Mónica (2006). Contando nuestra historia. Cuentos, fábulas y leyendas del Valle del Colca contados por niños. Arequipa: Universidad Católica de Santa María. 